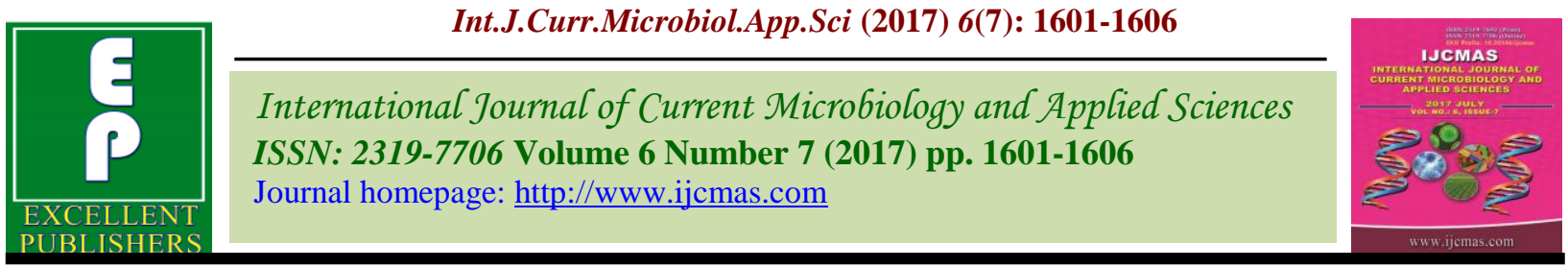

Review Article

https://doi.org/10.20546/ijcmas.2017.607.193

\title{
Effect of Shifting Animals from Groups on their Social Relationship and Performance
}

\author{
Deepandita Barman, Kotresh Prasad*, Sushil Kumar, Manish Ahirwar, \\ Mayamitta Saini and M.L. Kamboj \\ Livestock Production and Management, ICAR-NDRI, Haryana- 132001, India \\ *Corresponding author
}

\begin{abstract}
A B S T R A C T
Domestic animals are social creatures, established social hierarchical order with certain flocking instinct. Shifting causes re-establishment of hierarchical order in a new environment which aggravates behavioral patterns and is highly stressful to the livestock. The criteria before shifting animals from one group should be confirmation of pregnancy, level of milk production, BCS, age, time (afternoon or early evening milking to minimize

Keywords

Animals from

Groups on their

Social

Relationship,

Domestic animals.

Article Info

Accepted:

19 June 2017

Available Online:

10 July 2017

social disruption), labour, nutritional and social implications. Moving large numbers of animals at one time results in less fighting and social disruption in the group. The number of aggressive encounters can be reduced by housing cows in adjacent lots permitting limited close proximity and physical contact in free-stall barn designs. Shifting animals from different sources in high stocking density aggravates the incidence of fighting, vocalization, tension, anxiety, threat, butting, escape from group and stress. Animals after shifting spent less time in lying (10\%) than the normal environment $(65 \%)$ with reduced rumination, increased urination and defecation. Social pressure in a new group is due to different feed, milker and milking time which lead to less reaction to external stimuli, poor animal welfare and quality product problems. There is reduction in growth rate and milk production by $100 \mathrm{~g} / \mathrm{d}$ and 2.5 to $5.0 \%$, respectively due to decrease in eating time and increase in number of confrontations. The social impacts of regrouping last about minimum 7 days with potentially significant reduction in DMI and milk production. Young animal loss more body weight than older because of the fewer reserves of body fat and greater water content of relative to body weight. The stress induced by handling during shifting activated the sympathetic nervous system causes dysfunction of the pituitary, adrenal and thyroid glands thereby elevating the level of cortisol. Therefore, handlers should be well trained to reduce fear with minimum shifting period performed when necessary.
\end{abstract}

\section{Introduction}

Group incentive mechanisms produce enhanced performance but this depends on group conditions and the design of the incentive scheme (Fitzroy and Kraft, 1995). Domestic animals are instinctively social creatures that prefer to remain in flocks or herds. The flocking instinct differs among species, being very strong in sheep and less so in cattle and pigs. For this reason it is difficult to separate one sheep from the flock, but less difficult to separate a cow or a pig (Gonyou, 1993). Sudden isolation can be highly stressful to livestock (Rushen, 1986) and in the event of separation from the herd they can 
become highly agitated and injure themselves and their handlers. Establishment of new hierarchical order in the new environment in which animals find themselves during shifting period aggravates their behavioural patterns.

\section{Bond before shifting in different age groups in different species}

\section{Cattle}

Beef cows form a particularly strong bond with their calves because the calf is generally not weaned until several months after it born. Both the cow and calf will bawl for several days at the time of weaning. Whereas, dairy calves are usually weaned within a few hours or days of birth, the bond formed between mother and calf is not as strong. Because of this difference in time of weaning, the experience of shifting from the mother is usually less traumatic for dairy calves than it is for beef calves. It is a good management practice to make the separation of mother and calf permanent at the time of weaning.

\section{Sows}

Sows do not have as strong an ability to recognize their young as compared to other farm animals. This permits swine producers to even up litters of uneven size by moving young pigs from large litters to small litters when they are approximately the same age. This practice needs to occur shortly after the litters are born. Ewes and does will exhibit interspecies rearing the young. A ewe will nurse and care for an orphan kid; a doe will nurse and care for an orphan lamb.

\section{Chickens and turkeys}

The use of incubators in the production of chickens and turkeys and also ostrich and emu means that the maternal behavior in these species is rarely observed. Poultry raised in the older traditional manner demonstrate maternal behavior, caring for the young and protecting them from danger.

Major criteria to move cows from one group to another (Albright, 1978)

1. Confirmed pregnancy

2. Level of milk production

3. $\mathrm{BCS}$

4. Age

5. Time (afternoon or early evening milking to minimize social disruption )

6. Labour

7. Nutritional and Social Implications

\section{Moving animals between groups}

Cattle and sheep will follow a leader (Arnold, 1977). When one of the animals starts to move, the others will follow. Moving large numbers of cows at one time and moving only a few results in less fighting and social disruption of the group (Dumont et al., 2005). When deciding to move cows from one group to another, one needs to consider the labor, nutritional, and social implications of moving cows versus the increased feed efficiency resulting from grouping cows with similar nutritional and management requirements. The number of aggressive encounters can be reduced by housing cows in adjacent lots or groups, permitting some limited close proximity and physical contact (Albright and Arave, 1997). In free-stall barn designs, the fresh cow group should be adjacent to the high cow group, or the close-up group should be adjacent to the fresh cow group. As handling procedures are more stressful for an isolated cow, so several cows should be handled or moved at one time.

\section{Social effects of shifting between groups}

Cows are social animals and ranking within a group based on dominance. When cows are moved from one group to another, a new social order for that group must be established 
(Bouissou, 1970). The influence of a social change is transitory, which agrees with observations that dominance hierarchy within a group is stable and quickly established (Albright, 1978). Shifting animals from different sources in high stocking density with little or no space to establish social order aggravates the incidence of fighting and vocalization. This led to severe stress in the subordinate animals that continues to live under alarm, tension and anxiety (Kannan et $a l ., 2002)$. When cows are added to a socially stable group, the entire group disrupted through threat, butting and physical aggression until the added cows have found their place in the social structure of that group (Grant and Albright, 2001).

Mixing unfamiliar groups causes aggression amongst one another especially in bulls (Price and Tennesson, 1981). Social pressure in new group i.e. different feed, new milker, and a different milking time. Animals after shifting spent less time lying $(10 \%)$ than calves in a normal environment $(65 \%)$ with reduced rumination, increased urination and defecation (Kent and Ewbank, 1983). Animals react very little to external stimuli (Grandin, 1999).

Isolation of individual sheep or goats usually brings about signs of anxiety. Separations from the flock, herd, or social companions are important factors that cause sheep and goats to try to escape. Sheep and goats tend to follow one another even in activities such as grazing, bedding down, reacting to obstacles, and feeding (Hutson, 2007).

Stable social hierarchies develop in animals reared together in groups. These hierarchies become disrupted when unfamiliar animals are mixed together for transport to slaughter. The fighting to establish the new level of hierarchy can lead to animal welfare and meat quality problems.

\section{Production effects of shifting between groups}

Growth rate along the fattening period: unmixed group $(1700 \mathrm{~g} / \mathrm{d})>$ mixed group $(1600 \mathrm{~g} / \mathrm{d})$ reduces growth maintaining affliliative bond.2.5 to $5.0 \%$ greater decrease in milk production due to social disturbances compared with control animals that were not regrouped (Albright, 1978). The eating time decreased and number of confrontations increased substantially during the first day (Konggaard and Krohn, 1978). Early lactation cows exhibited the greatest reduction in DMI and milk production (Grant and Albright, 2001).About 1 wk is required for the dominance hierarchy to become reestablished and stabilized after new cows were introduced into the group (Schein and Fohrman, 1955). The effect of regrouping appears is variable.

The social impacts of regrouping last about 3 days and almost always less than 7 days with potentially significant reduction in DMI and milk production. Young calves loss more body weight than older calves during cowcalf shifting separately, with the mediumaged calves showing intermediate values. Young animals have fewer reserves of body fat and greater water content of relative to body weight (Marquezini et al., 2013).

\section{Physiology effects of shifting between groups}

The greatest stress induced by handling at the start of shifting, which activated the sympathetic nervous system, including the adrenal medulla and finally the adrenal cortex (Minka and Ayo, 2010). It is studied that intensively reared dairy cattle had much lower stress responses to being handled and restrained than cattle in an extensive environment (Laye et al., 1992). It is also due to dysfunctions of the pituitary, adrenal and 
thyroid glands (Hartung, 2003). Regrouped pigs showed elevated cortisol and CPK levels, and evidence of muscle glycogen depletion, indicating that fighting is a stressful experience (Warriss, 1994).

\section{Aids of shifting animals}

The goals of shifting should be to minimize stress to each individual animal, reduce fear, and maintain calmness in all animals. All handlers should be trained in the natural behavior of the species including their flight zone and in proper handler movement and interaction, and be able to recognize any signs of distress, anxiety, or behaviors that may result in injury or stress to the animals. The period of shifting should be the minimum. Electrical immobilization must not be used as a method of restraint. It is highly aversive to cattle and sheep (Grandin et al., 1987; Lambooy, 1985; Pascoe and McDonnell, 1985; Rushen, 1986). When possible, animals should be shipped in groups of uniform weight, sex, and species.

\section{Causes of adverse effects}

Unfamiliar conditions, type of flooring material, a change in lighting or penning walls can have worse effect if the livestock are being driven along aggressively without being given time to investigate the new area (Grandin, 1989). Rough handling and unexpected loud noises are highly stressful to stock (Grandin, 1989; Talling et al., 1996). Sounds from people such as yelling or whistling had a greater effect on heart rate of cattle than equipment sounds such as banging gates (Waynert et al., 1999).

The social effects indicate that greater emphasis should be placed on developing animal welfare and shifting-handling guidelines that are species specific (Bradshaw et al., 1996). Research clearly shows that animals that are handled in a negative manner and fear humans have lower weight gains, fewer piglets, and give less milk and reduced egg production (Hemsworth, 1981; Barnett et al., 1992; Hemsworth et al., 2000).

In conclusion, shifting causes reestablishment of hierarchical order in a new environment which aggravates behavioural patterns and is highly stressful to the livestock. The criteria before shifting animals from one group should be confirmation of pregnancy, level of milk production, BCS, age, time, labour, nutritional and social implications. Animals after shifting spent less time in lying, reduction in rumination, DMI, less reaction to external stimuli, reduction in growth rate and milk production, increased urination and defecation, poor animal welfare and quality product problems. The stress induced by handling during shifting activated the sympathetic nervous system causes dysfunction of the pituitary, adrenal and thyroid glands thereby elevating the level of cortisol. Therefore, handlers should be well trained to reduce fear with minimum shifting period performed when necessary.

\section{References}

Albright, J.L. 1978. Social considerations in grouping cows in large dairy herd management. C. J. Wilcox and H. H. Van Horn, ed. University Press of Florida, Gainesville. Pp: 757-779

Albright, J.L. and C.W. Arave. 1997. The behavior of cattle. CAB International, Wallingford, UK.

Arnold, G.W. 1977. An analysis of spatial leadership in a small field in a small flock of sheep. Appl. Anim. Ethol., 3: 263-270.

Barnett, J.L., Hemsworth, P.H. and Newman, E.A. 1992. Fear of humans and its relationships with productivity in laying hens at commercial farms. Br. Poult. 
Sci., 33: 699-710.

Bouissou, M.F. 1970. Role du contact physique dans la manifestation des relations hierarchiques chez les bovins. Consequences pratiques. Ann. Zootech., (Paris) 19: 279-285.

Bradshaw, R.H., Parrott, R.F., Goode, J.A., Lloyd, D.M., Rodway, R.G. and Broom. D.M. 1996. Behavioural and hormonal responses of pigs during transport: effect of mixing and duration of journey. Animal Sci., 62: 547-554.

Dumont, B., Boissey, A. and Archard, C. 2005. Consistency of order in spontaneous group movements allows the measurement of leadership in a group of grazing heifers. Appl. Anim. Behav. Sci., 95: 55-66.

Fitzroy, F.R. and Kraft, K. 1995. On the choice of incentives in firms. $J$. Economic Behavior and Organization, 26(1): 145-160.

Gonyou, H. 1993. Animal welfare: definitions and assessment. J. Agri. and Env. Ethics Supplement, 2: 37-43.

Grandin, T. 1989. Voluntary acceptance of restraint by sheep. Appl. Anim. Behav. Sci., 23: 257.

Grandin, T. 1999. Behavioural principles of livestock handling. Department of Animal Science, Colorado State University, Fort Collins, Colorado, U.S.A.

Grant, R.J. and Albright, J.L. 2001. Effect of Animal Grouping on Feeding Behavior and Intake of Dairy Cattle. Faculty Papers and Publications in Animal Science, Paper 710.

Grandin, T. 1987. Animal handling. In Farm Animal Behavior. E. O. Price, ed. Vet. Clin. North Am. Food Anim. Pract., 3: 323-338.

Hartung, J. 2003. Effects of transport on health of farm animals. Vet. Res. Commun., 27: 525-527.

Hemsworth, P.H. 1981. The influence of handling by humans on the behavior, growth and corticosteroids in the juvenile female pig. Horm. Behav, 15: 396-403.

Hemsworth, P.H., Coleman G.J., Barnett J.L., and Borg. S. 2000. Relationships between human-animal interactions and productivity of commercial dairy cows. J. Anim. Sci., 78: 2821-2831.

Hutson, G.D. 2007. Behavioural principles of sheep handling. In: T. Grandin, (ed.), Livestock Handling and Transport. CABI Publishing, Wallingford, UK, pp. 155-174

Kannan, G., Terril, T.H., Kouokou, B., Gelaye, S. and Amoah, E.A. 2002. Simulated preslaughter holding and isolation effects on stress responses and live weight shrinkage in meat goats. $J$. Anim. Sci., 80: 1771-1780.

Kent, J.E. and Ewbank, R.1983. The effect of road transportation on the constituent and behaviour of calves of six months old. Br. Vet. J., 139: 228-235.

Konggaard, S.P. and Krohn, C.C. 1978. Performance of first-calf heifers in two different grouping systems. Rep. Nat. Inst. Anim. Sci., Copenhagen, Denmark.

Lambooy, E. 1985. Electro-anesthesia or electro-immobilization of calves, sheep and pigs by Feenix Stock still. Vet. Q. 7: 120-126.

Lay, C., Friend T.H., Randel, R., Bowers, C.C, Grissom, K.K. and Jenkins, O.C. 1992. Behavioral and physiological effects of freeze and hot iron branding on crossbred cattle. J. Anim. Sci., 70: 330-336.

Marquezini, G.H.L., Mercadante, V.R.G., Bischoff, K.M., Black, T.E., DiLorenzo, N., Bird, S.L., Funnell, B.J., Klein, S.I., Dahlen, C.R., Larson, J.E. and Lamb, G.C. 2013.Effects of temporary calf removal before fixed-time artificial insemination on pregnancy rates and subsequent calf performance in suckled 
beef cows. J. Anim. Sci., 91: 24142425.

Minka, N.S. and Ayo, J.O. 2010. Physiological responses of food animals to road transportation stress. African $J$. Biotech., Vol. 9(40), pp. 6601-6613.

Pascoe, P.J., and McDonnell, W.N. 1985. Aversive conditions used to test the humaneness of a commercial electroimmobilization unit in cattle. Vet. Surg., 14: 75. (Abstr.)

Price, M. and Tennessen, T. 1981. Preslaughter management and dark cutting in the carcasses of young bulls. Canadian J. Ani. Sci., 61: 205-206.

Rushen, J. 1986. Aversion of sheep to electroimmobilization and physical restraint. Appl. Anim. Behav. Sci., 15: 315-324.

Schein, M.W. and Fohrman, M.H. 1955.
Social dominance relationship in a herd of dairy cattle. Brit. J. Anim. Behav., 3: 45.

Talling, J.C., Waran N.K., Wathes, C.M., and Lines, J.A. 1998. Sound avoidance domestic pigs depends on characteristics of the signal. Appl. Anim. Behav. Sci., 58: 255-266.

Waynert, D.E., Stookey, J.M., SchwartzkopfGerwein, J.M., Watts, C.S. andWaltz, C.S. 1999. Response of beef cattle to noise during handling. Appl. Anim. Behav. Sci., 62: 27-42.

Warriss, P.D., Brown, S.N., Adams, S.J. and Corlett, I.K. 1994. Relationships between subjective and objective assessments of stress at slaughter and meat quality in pigs. Meat Sci., 38: 329340.

\section{How to cite this article:}

Deepandita Barman, Kotresh Prasad, Sushil Kumar, Manish Ahirwar, Mayamitta Saini and Kamboj, M.L. 2017. Effect of Shifting Animals from Groups on their Social Relationship and Performance. Int.J.Curr.Microbiol.App.Sci. 6(7): 1601-1606. doi: https://doi.org/10.20546/ijcmas.2017.607.193 